\title{
Merging Models of Hepatitis C Virus Pathogenesis
}

Hans L. Tillmann, M.D., Michael P. Manns, M.D., and K. Lenhard Rudolph, M.D.

In the above-mentioned article, published in Seminars in Liver Disease 2005; Volume 25, Number 1, pages 84-92, the reference citations are incorrect. The citations have been corrected and the article has been reprinted online in its entirety. The online article can be found in Seminars in Liver Disease 2005; Volume 25, Number 3, through Thieme-Connect at www.thieme-connect.com.

Primary Biliary Cirrhosis; Editor in Chief, Paul D. Berk, M.D.; Guest Editors, M. Eric Gershwin, M.D., John M. Vierling, M.D. Seminars in Liver Disease, volume 25, number 3, 2005. Address for correspondence and reprint requests: Dr. K. Lenhard Rudolph, Department of Gastroenterology, Hepatology, and Endocrinology, Medical School of Hannover, Carl-Neuberg-Str. 1, 30625 Hannover, Germany. E-mail: Rudolph. Lenhard@MH-Hannover.de; or Hans L. Tillmann, Medizinische Klinik und Poliklinik II, Universität Leipzig, Philipp-Rosenthal-Str. 27, 04103 Leipzig, Germany. E-mail: hans.tillmann@medizin.uni-leipzig.de. Copyright (C) 2005 by Thieme Medical Publishers, Inc., 333 Seventh Avenue, New York, NY 10001, USA. Tel: +1(212) 584-4662. 0272-8087,p;2005,25,03,378,378,ftx,en;sld00363x. 